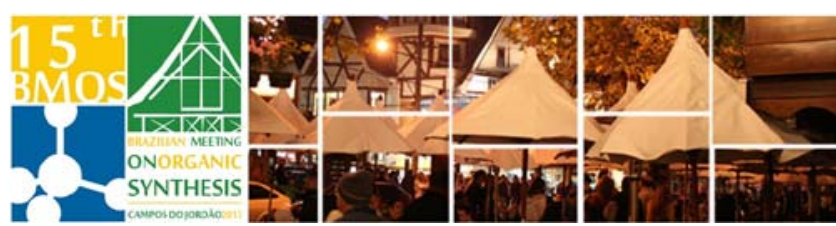

\title{
LDA Conjugate Addition to a Morita-Baylis-Hillman Ester: Experimental and DFT-based Theoretical Observations
}

\author{
Bruno A. Sousa, Antonio A. S. Paulino, Ataualpa A. C. Braga, Romulo A. Ando and \\ Alcindo A. Dos Santos* \\ Instituto de Química, Universidade de São Paulo, Av. Prof. Lineu Prestes, 748, Cx.P. 26077, CEP: 05508- \\ 000 São Paulo, Brazil. \\ *e-mail corresponding author: alcindo@iq.usp.br
}

Keywords: Density Functional Theory, Morita-Baylis-Hillman, Conjugate Addition

\section{INTRODUCTION}

The Morita-Baylis-Hillman (MBH) reaction is well known for providing valuable building blocks in organic synthesis. In the last few years it has been demonstrated that not only the $\mathrm{MBH}$ adducts itself can be useful intermediates, but also, its derivatives. The corresponding esters of $\mathrm{MBH}$ adducts (acetates, in most cases) have been extensively described in the literature due to its particular reactivity towards the attack of different nucleophiles ${ }^{1}$ (Scheme 1).

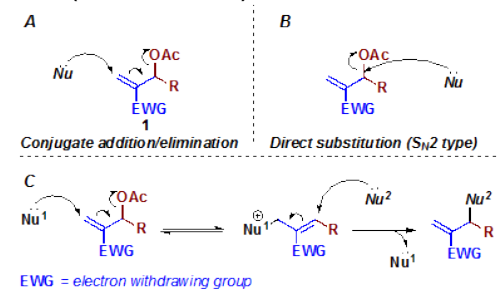

Scheme 1. The reactivity of $\mathrm{MBH}$ acetates towards the attack of different nucleophiles.

the use of lithium amides is a very frequent strategy for synthetic chemists in order to produce reactive anionic intermediates. In the case of a $\mathrm{MBH}$ ester, the usual chemistry of lithium amides may not be absolute as already observed in different situations ${ }^{2}$. Herein we present an example of LDA conjugate addition to a $\mathrm{MBH}$ ester, also providing a Density Functional Theory (DFT)-based description of the reaction pathway, supporting the experimental unexpected results.

\section{RESULTS AND DISCUSSION}

During some studies on $\mathrm{MBH}$ esters transformations we have decided investigate the possibility of a 6 exo-trig type cyclization of these esters to produce six-membered lactones (3). This proposition was based on the formation of an enolate (2) by means of a strong base for further conjugate addition to the terminal activated double bond (Scheme 2).

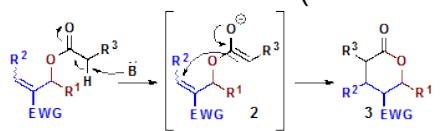

Scheme 2. Initial proposition for the lactonization reaction of $\mathrm{MBH}$ esters.
Compound 4 was treated with LDA in order to promote its enolization aiming to generate the lactone 5. Instead, the lactone, compound $\mathbf{6}$ was isolated in $74 \%$ yield. Theoretical calculations based on DFT were conduced in order to provide reliability to the experimental observation that LDA can actually act as a nucleophile rather than a base. The energy profile for the competing reaction mechanisms are depicted in Scheme 3.

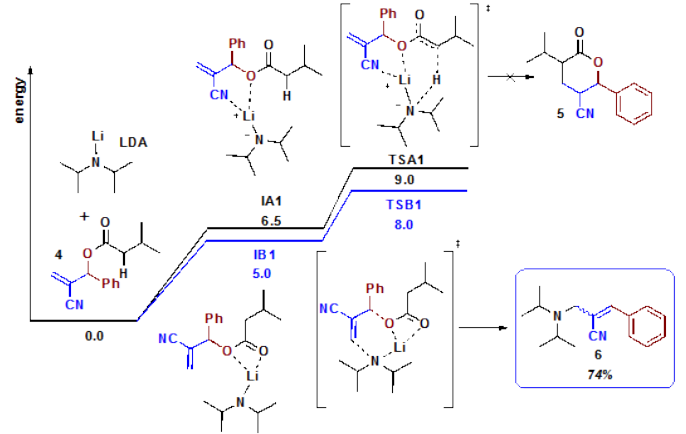

Scheme 3. The computational data were obtained by means of the B3LYP functional and Pople bases (6$31 \mathrm{G}+(\mathrm{d})$ for every atom.

\section{CONCLUSION}

We have provided experimental and theoretical data for a non-expected conjugate addition of LDA to a $\mathrm{MBH}$ ester. We have also calculated the whole reaction profile for both competing reactions, showing that despite the acidity of $\alpha$-carboxyl protons, this kind of $\mathrm{MBH}$ ester cyclization cannot be achieved.

\section{ACKNOWLEDGEMENTS}

The authors would like to thank FAPESP, CNPq, Capes and NAPCatSinQ for the financial support.

\section{REFERENCES}

${ }^{1}$ Basavaiah, D.; Reddy, B. S.; Badsara, S. S. Chem. Rev. 2010, 110, 5447.

${ }^{2}$ Ma, Y.; Hoepker, A. C.; Gupta, L.; Faggin, M. F.; Collum, D. B. J. Am. Chem. Soc. 2010, 132, 15610. 